ISSN = 1980-993X - doi:10.4136/1980-993X
www.ambi-agua.net
E-mail: ambi-agua@agro.unitau.br
Tel.: (12) 3625-4212

\title{
Estudo geofísico em aterro controlado disposto sobre rochas fraturadas
}

\author{
(http://dx.doi.org/10.4136/ambi-agua.193) \\ César Augusto Moreira ${ }^{1}$, Mônica Teixeira de Oliveira², Ariveltom Cosme da Silva ${ }^{3}$ \\ ${ }^{1}$ Prof. Assistente Doutor - Universidade Estadual Paulista (UNESP) - Campus de Rio Claro (SP) - Brasil \\ e-mail: cesargeologia@yahoo.com.br \\ ${ }^{2}$ Graduação em Geofísica -Universidade Federal do Pampa (UNIPAMPA) - Campus Caçapava do Sul (RS) - \\ Brasil, e-mail - monyckaolyveira@hotmail.com \\ ${ }^{3}$ Professor Adjunto - Universidade Federal do Rondônia (UNIR) - Campus de Jí-Paraná (RO) - Brasil \\ e-mail. ariveltom@unir.br
}

\section{RESUMO}

A geofísica é uma importante ferramenta de investigação de áreas contaminadas, utilizada na caracterização de contrastes de propriedades físicas no ambiente geológico na presença de substâncias poluentes. Este trabalho aplica os métodos geofísicos da Eletrorresistividade e do Potencial Espontâneo numa área de disposição de resíduos sólidos desativada, localizada no município de Caçapava do Sul, RS. O aterro está assentado sobre rochas metamórficas fraturadas. Foram realizadas 8 linhas de caminhamento elétrico e 288 medidas de potencial elétrico natural. Também foram realizadas 83 medidas de direção e sentido de fraturas. A aplicação do método do potencial espontâneo permitiu detectar o sentido do fluxo d'água subterrâneo. As medidas de resistividade elétrica permitiram identificar anomalias de baixa intensidade associadas à presença de chorume. Houve uma relação entre zonas anômalas com as direções de fraturas.

Palavras-chave: geofísica; resistividade elétrica; voltagem; chorume; fraturas.

\section{Geophysical study in waste landfill localized above fractured rocks}

\begin{abstract}
Geophysical survey is an important method for investigation of contaminated areas used in the characterization of contrasting physical properties in the presence of pollutants. This work applied the geophysical methods of Electrical Resistivity and Self Potential in waste landfill, located in Caçapava do Sul city, RS. The landfill is located over fractured metamorphic rocks. Eight lines of electrical profiling with 288 measures of self potential were done. In addition, 83 measurements of direction and dip of fractures were taken. The application of spontaneous potential method permitted to detect the direction of groundwater flow. The electrical resistivity measurements allowed the identification of low-intensity anomalies associated with the presence of leachate. There is a relationship between anomalous zones and the directions of fractures.
\end{abstract}

Keywords: geophysics; electrical resistivity; voltage; leachate; fractures. 


\section{INTRODUÇÃO}

A poluição dos solos gera um grande problema para o meio ambiente, inclusive provoca grande impacto nas águas subterrâneas. Vários estudos têm sido realizados em áreas de deposição de resíduos sólidos, onde há suspeita de contaminação provocada pelo líquido proveniente da degradação de resíduos orgânicos, caracterizado por baixo pH e elevada demanda química e biológica por oxigênio. Tais características tornam o chorume um composto com caráter contaminante (Hamada, 1999).

O gerenciamento de resíduos sólidos urbanos tem sido um verdadeiro desafio aos gestores públicos, devido a problemas como áreas disponíveis, licenciamento ambiental, custos de transporte, dentre outros. A situação dos municípios brasileiros referente à disposição final dos resíduos sólidos urbanos é: 37,0\% dos resíduos são depositados em aterros sanitários, 36,2\% são depositados em aterros controlados, 22,5\%, em vazadouro a céu aberto (lixão), 2,9\%, em estação de compostagem, 1,0\%, em estação de triagem, e 0,5\%, incinerados (Juca, 2003; IBGE, 2002).

Os lixões podem ser definidos como o simples descarte de lixo, sem quaisquer projetos técnicos que visam minimizar os impactos resultantes ao ambiente, como impermeabilização do substrato ou sistemas de coleta de chorume. A omissão dos órgãos de fiscalização ou o simples descaso da população, muitas vezes resultam no descarte clandestino de resíduos, geralmente em áreas inapropriadas, como nascentes, rios e áreas de proteção permanente.

Caso o solo sob os resíduos seja permeável e desprotegido, o chorume pode atingir o nível freático. A geração de chorume pode ultrapassar quinze anos após o final da deposição de lixo, dependendo de vários fatores (Possamai et al., 2007).

Plumas de contaminação provenientes de aterros são frequentemente caracterizadas por quatro grupos de poluentes (Christensen et al., 1994):

- Matéria orgânica dissolvida, expressa pela demanda química de oxigênio ou carbono orgânico total, incluindo $\mathrm{CH}_{4}$, ácidos graxos voláteis e compostos mais refratários como húmicos e fúlvicos.

- Componentes inorgânicos: $\mathrm{Ca}, \mathrm{Mg}, \mathrm{Na}, \mathrm{K}, \mathrm{NH}_{4}{ }^{+}, \mathrm{Fe}, \mathrm{Mn}, \mathrm{Cl}, \mathrm{SO}_{4}{ }^{2+}, \mathrm{HCO}_{3}{ }^{-}$.

- Metais pesados: Cd, Cr, $\mathrm{Cu}, \mathrm{Pb}, \mathrm{Ni}$ e Zn.

- Compostos orgânicos derivados de petróleo, que incluem hidrocarbonetos aromáticos, fenóis e compostos clorados alifáticos.

Outros compostos podem ser encontrados nesse ambiente, como B, As, Se, Ba, Li, Hg, e Co, sempre em concentrações muito baixas e de importância secundária. A detecção e as concentrações desses elementos ou compostos podem variar devido a mudanças das fases de oxidação/redução e/ou alterações sazonais.

Reações exotérmicas de controle biogeoquímico são reconhecidas por causarem aumento da temperatura na água subterrânea em aterros, devido ao ingresso de chorume das partes rasas do aterro. Consequentemente, ocorre grande atividade de bactérias e reações de troca iônica de forma progressiva nas porções inferiores do aterro; tais reações podem resultar em alterações na porosidade dessas porções e no substrato geológico em contato direto.

O chorume que adentra num aquífero anaeróbico é lentamente biodegradado, com a produção de ácidos graxos que podem reagir com os materiais do aquífero, com consequentes mudanças no fluxo químico próximo ao nível freático (Bennett e Siegel, 1987). Num ambiente com baixos teores de oxigênio, materiais inorgânicos contidos no chorume podem ser dissolvidos na água subterrânea.

Abaixo do nível freático, a mistura de chorume com a água subterrânea e reações com o material do substrato formam uma pluma eletricamente condutiva. Alem dos limites da 
pluma, a quantidade de sólidos totais dissolvidos (STD) e a condutividade elétrica apresentam valores intrínsecos aos do ambiente natural (Bennett e Siegel, 1987).

A condutividade elétrica pode ser medida em termos de STD, devido à associação do íon cloreto como indicador conservativo da presença de chorume em amostras de água (Baedecker e Apgar, 1984). O trabalho de Bell e Jermy (1995), dentre muitos outros, descreve a relação direta entre decréscimo de STD e da condutividade elétrica com o distanciamento do aterro.

Atualmente os métodos geofísicos são amplamente utilizados nesse tipo de estudo devido a sua rapidez e custo relativamente baixo quando comparados a outras técnicas de investigação. Os principais métodos geofísicos para investigação de contaminantes são: eletrorresistividade, potencial espontâneo (SP), radar de penetração no solo (GPR) e, eventualmente, magnetometria (CETESB, 2001).

No aterro municipal de Cordeirópolis (SP), Moreira et al. (2009) utilizaram medidas de resistividade elétrica, obtidas com a técnica de caminhamento elétrico, combinadas com medidas de pH (potencial hidrogeniônico) e Eh (potencial de oxidação) em amostras de solo para avaliar o comportamento geoquímico de resíduos sólidos enterrados, durante o processo de degradação de matéria orgânica. Os estudos foram realizados em valas fechadas entre dezembro de 2001 a dezembro de 12/2007. Os resultados mostraram a presença de valores de resistividade abaixo de $30 \Omega$.m nas linhas realizadas sobre as valas, sugerindo a presença de chorume. A correlação temporal entre $\mathrm{pH}$ e Eh pode indicar as condições geoquímicas predominantes as quais estão associadas ao padrão de resistividade elétrica. Assim, baixos valores de resistividade associados a baixos valores de $\mathrm{pH}$ e elevados valores de Eh indicam a possível existência de uma pluma de contaminação.

O trabalho de Moreira e Braga (2009a) apresenta os resultados de aplicação dos métodos de eletrorresistividade e polarização induzida em uma área industrial contaminada por benzeno, tolueno, xileno, 1,2 dicloroetano e sais inorgânicos. São discutidas as alterações físicas do meio contaminado a partir dos resultados obtidos e na perspectiva dos processos de biodegradação de compostos de fase líquida não aquosa (NAPL), além dos indícios de mineralização na porção central e adjacências da área contaminada. Os resultados descrevem anomalias tanto de baixa quanto de alta resistividade, confirmada como fase contaminante por meio de análises químicas. Essa aparente contradição pode refletir processos de degradação, associada ao tempo de residência de contaminantes no ambiente, por meio da geração de subprodutos que alteram as propriedades físicas do meio, principalmente pela dissolução mineral por ação de ácidos orgânicos e pela neoformação de minerais de óxidos e hidróxidos de ferro.

O presente trabalho apresenta os resultados de investigação geofísica numa área de disposição de resíduos sólidos domiciliares, assentado sobre rochas fraturadas, localizado no município de Caçapava do Sul (RS). Os objetivos são: definir a espessura de resíduos enterrados, mapear a presença de caminhos preferenciais de fluxo associado ao fraturamento do substrato.

\section{MATERIAIS E MÉTODO}

\subsection{Localização e descrição da área}

A área de estudos foi um local de disposição de resíduos sólidos domiciliares, localizado no Rincão dos Bitencourt, zona rural do município de Caçapava do Sul (RS) (Figura 1). O município possui cerca de 33.060 habitantes (IBGE, 2009) com produção diária atual em torno de 12 toneladas de lixo doméstico.

A área de estudos foi utilizada durante 14 anos, entre 1980 e 1994. Durante esse período foram depositadas cerca de 28.000 toneladas de resíduos a céu aberto, que resultaram em poluição ao meio ambiente e transtornos aos moradores próximos, devido á proliferação de 
insetos e ao forte odor. Essa área é limitada a norte e a sul por duas drenagens, que foram significativamente impactadas devido à ausência de quaisquer sistemas de coleta e armazenamento de chorume (Caçapava do Sul,1996).

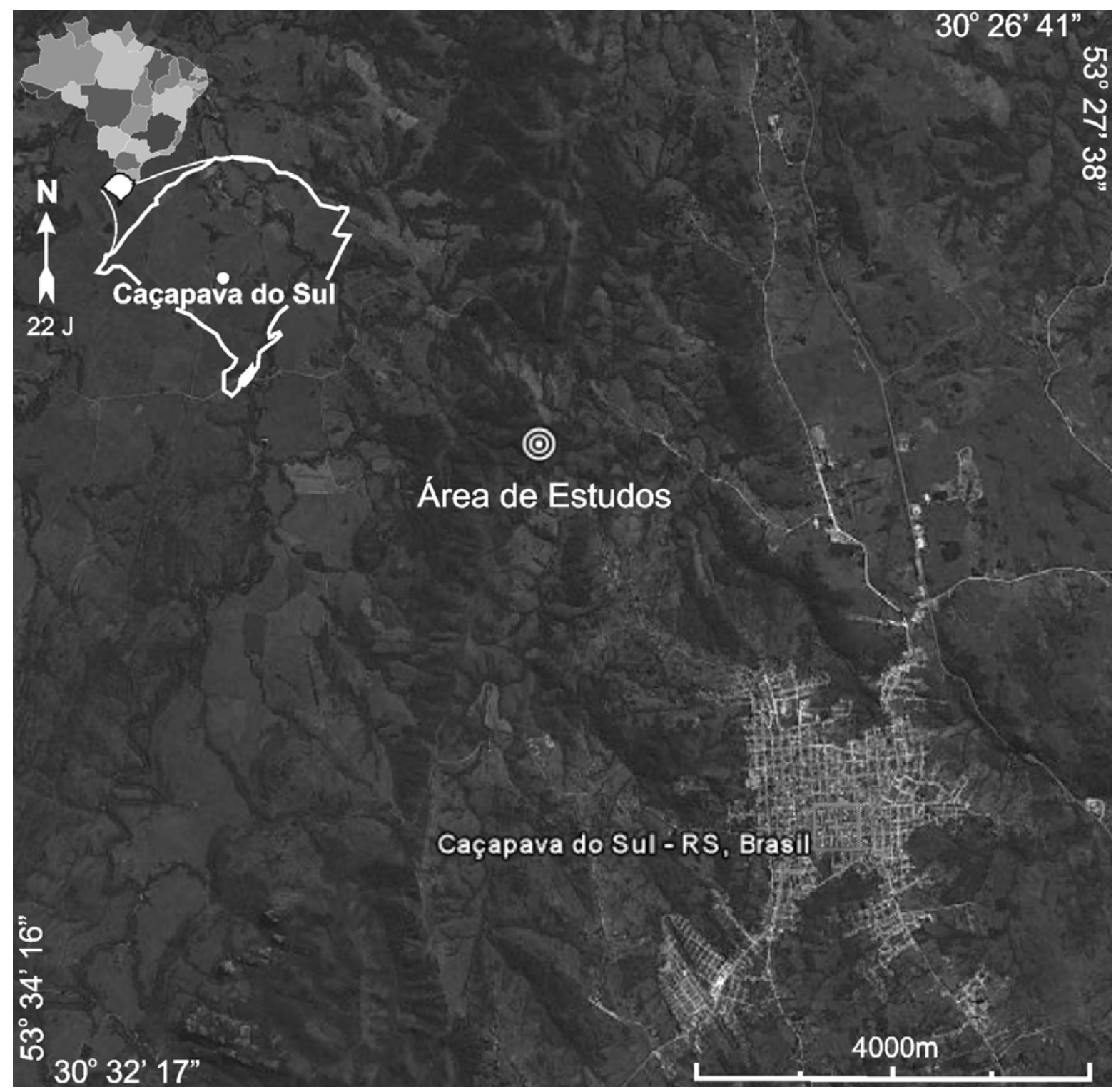

Figura 1. Localização da área de estudo.

Source: (Google Earth, 2010).

O contexto geológico da área compreende rochas do Complexo Metamórfico Vacacaí, constituído por uma unidade vulcânica e uma unidade vulcanossedimentar (Brasil, 2008). O Complexo Metamórfico Vacacaí é limitado, principalmente, por coberturas vulcanossedimentares não metamórficas e intrudida por granitos sintranscorrentes, tardi a pós-tectônicos.

A área de estudos está assentada sobre a unidade vulcanossedimentar, que ocorre em uma faixa de orientação variável entre N-S e NE-SW, com inicio a norte da Suíte Granítica Caçapava do Sul até o extremo-sul, com formato de arco com concavidade voltada para norte (Brasil, 2000). Por sua vez, Bitencourt (1983) caracterizou dois eventos metamórficos regionais, dos quais o mais antigo é representado por paragêneses compatíveis com o fácies anfibolito; o segundo evento é essencialmente retrogressivo e apresenta associações mineralógicas compatíveis com a fácies xisto verde, relacionado à fase de deformação responsável pela xistosidade regional. 
A Suíte Granítica Caçapava do Sul compreende dois corpos graníticos intrusivos no Complexo Metamórfico Vacacaí. O corpo maior possui uma forma ovulada cujo eixo maior, com cerca de $25 \mathrm{~km}$ de extensão, orientado segundo uma direção N-S e denomina a suíte. Essa suíte é constituída predominantemente de monzo e sienogranitos com participação subordinada de rochas de composição granodiorítica a tonalítica representadas principalmente na borda oeste do corpo principal (Brasil, 2000).

O Complexo Metamórfico Vacacaí é localmente caracterizado por anfibolitos, mica-xisto e talco-xisto. A área de pastagem adjacente ao aterro apresenta exposições de granito e contato discordante com xistos do complexo metamórfico. O granito apresenta feições de metamorfismo, bandamento pouco pronunciado, cristais de coloração rosa. O fraturamento observado nos xistos possui prolongamento para o granito.

\subsection{Eletrorresistividade}

O método da eletrorresistividade emprega uma corrente elétrica artificial que é introduzida no terreno através de dois eletrodos, com o objetivo de medir o potencial gerado em outros dois eletrodos nas proximidades do fluxo de corrente, permitindo assim calcular a resistividade real ou aparente em subsuperfície (Lowrie, 2007).

A resistividade elétrica esta relacionada aos mecanismos de propagação de corrente elétrica nos materiais. Em geral, a propagação de corrente elétrica em solos e rochas ocorre predominantemente devido ao deslocamento de íons dissolvidos na água contida nos poros e fissuras, sendo afetada principalmente pela composição mineralógica, porosidade, teor em água, quantidade e natureza dos sais dissolvidos (Elis et al., 2004; Milsom, 2003).

Essas condições possibilitam a aplicação da Eletrorresistividade em estudos ambientais e hidrogeológicos, nos quais a presença de água nos poros e descontinuidades da rocha e, eventualmente, de contaminantes ricos em sais, pode ser investigada pelo método.

O método de potencial espontâneo consiste em medidas de campo elétrico natural gerado a partir de diversos fenômenos físicos e físico-químicos, por meio de um medidor de voltagem. Outros potenciais são efeitos naturais, devido à ação mecânica ou eletroquímica. $\mathrm{O}$ fenômeno eletroquímico é a principal fonte de geração de potencial (Milsom, 2003).

Este trabalho adota a técnica de caminhamento elétrico com arranjo de campo dipolodipolo para medidas de resistividade e o arranjo de base fixa para medidas de potencial espontâneo. O arranjo dipolo-dipolo consiste em polos de injeção de corrente e polos de leitura de potencial, com espaçamento entre os eletrodos de corrente e potencial. O arranjo base fixa utiliza um eletrodo fixo em um ponto fora da área de estudos, a montante do fluxo d'água subterrânea. Outro eletrodo é movido e fixado nos pontos pré-determinados. Com essa técnica o potencial total é medido diretamente em cada estação.

Para a aquisição de dados foram realizadas 8 linhas de caminhamento com espaçamento de $10 \mathrm{~m}$ entre elas. As linhas de caminhamento elétrico 1 a 7 foram realizadas sobre a área de resíduos enterrados, enquanto que a linha 8 foi realizada no limite do aterro (Figura 2). Foi adotado espaçamento de $5 \mathrm{~m}$ entre eletrodos e investigação de 10 níveis de profundidade, juntamente com 288 medidas de potencial espontâneo.

Foi utilizado o resistivímetro SYSCAL PRO. Esse equipamento realiza leituras de resistividade elétrica, cargabilidade elétrica e voltagem. Os dados de resistividade foram processados no programa RES2DINV (Loke e Barker, 1996). Os dados de potencial espontâneo foram processados por interpolação simples por meio do software Surfer 8.0. 


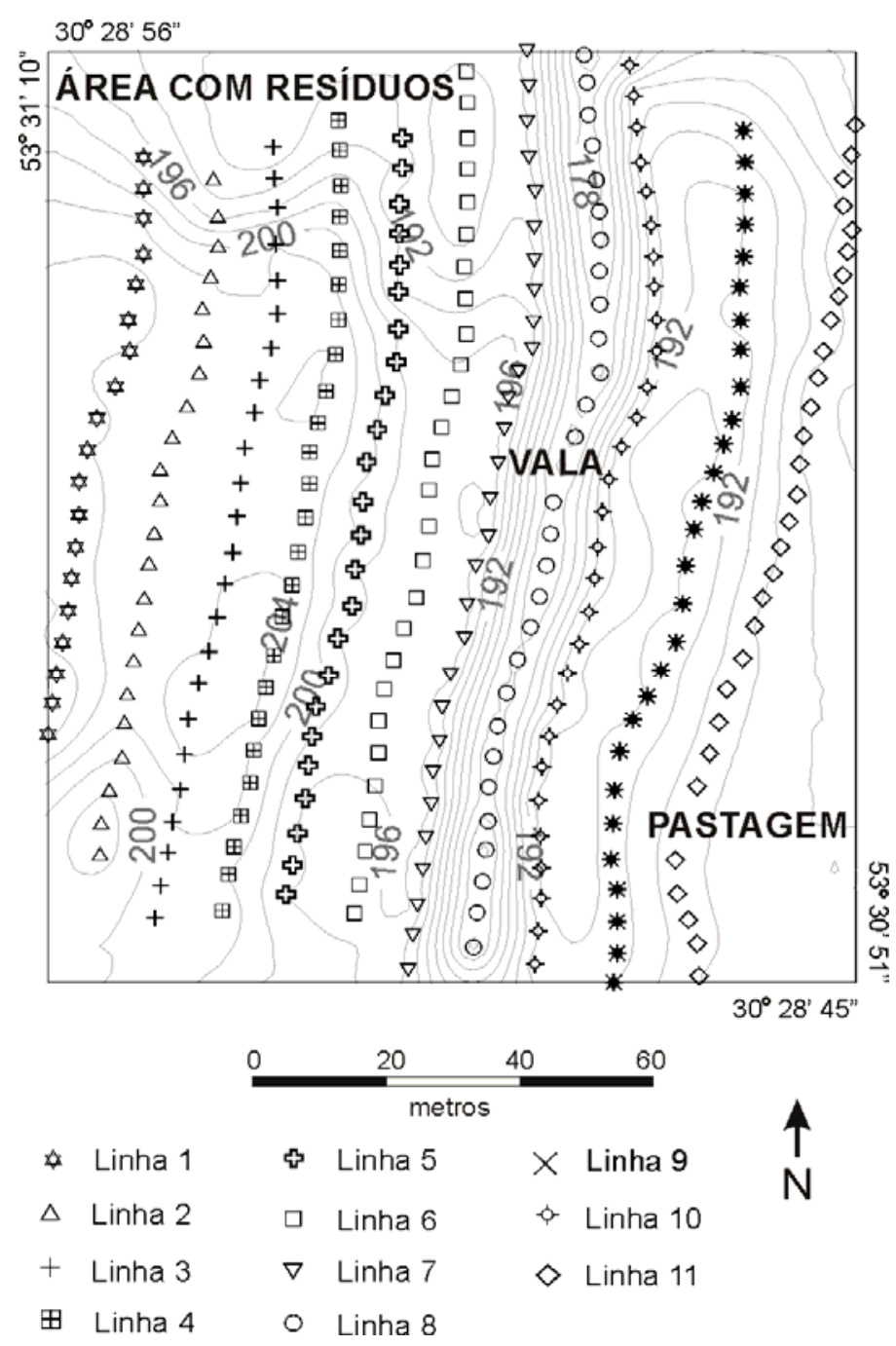

Figura 2. Pontos de leitura de potencial espontâneo dispostos em linha com topografia da área. Foram realizadas medidas de resistividade elétricas apenas nas linhas 1 a 8.

\section{RESULTADOS E DISCUSSÃO}

Foram realizadas 83 medidas de direção e sentido de fraturas, em exposições de rochas aflorantes no início e no final das linhas de caminhamento. Os dados estruturais estão representados na forma de estereograma e indicam o predomínio de direções de fraturas entre $\mathrm{N} 90^{\circ}$ a $\mathrm{N} 110^{\circ}$ e mergulho de $90^{\circ}$ (Figura 3).
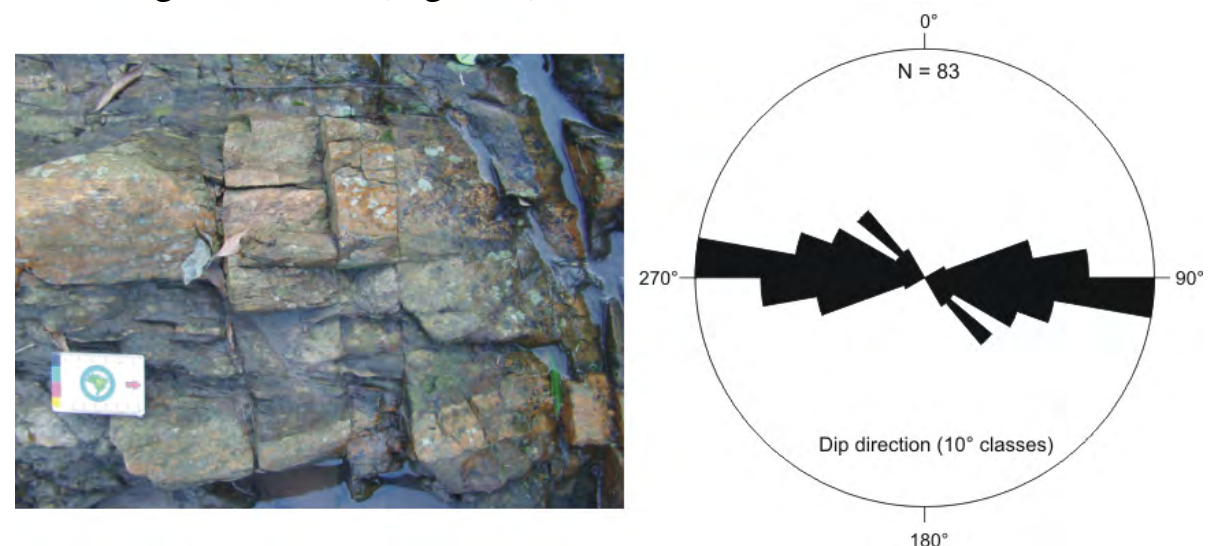

Figura 3. Fraturas observadas na área e resultado das medidas estruturais 
O mapa de potencial espontâneo indica que grande parte da área apresenta valores entre $-30 \mathrm{mV}$ a $30 \mathrm{mV}$. Áreas restritas apresentam valores superiores a $30 \mathrm{mV}$. Áreas alongadas com valores entre $-30 \mathrm{mV}$ a $10 \mathrm{mV}$ estão presentes tanto no lado da pastagem (leste da vala), quanto para o lado do aterro (oeste da vala) (Figura 4).

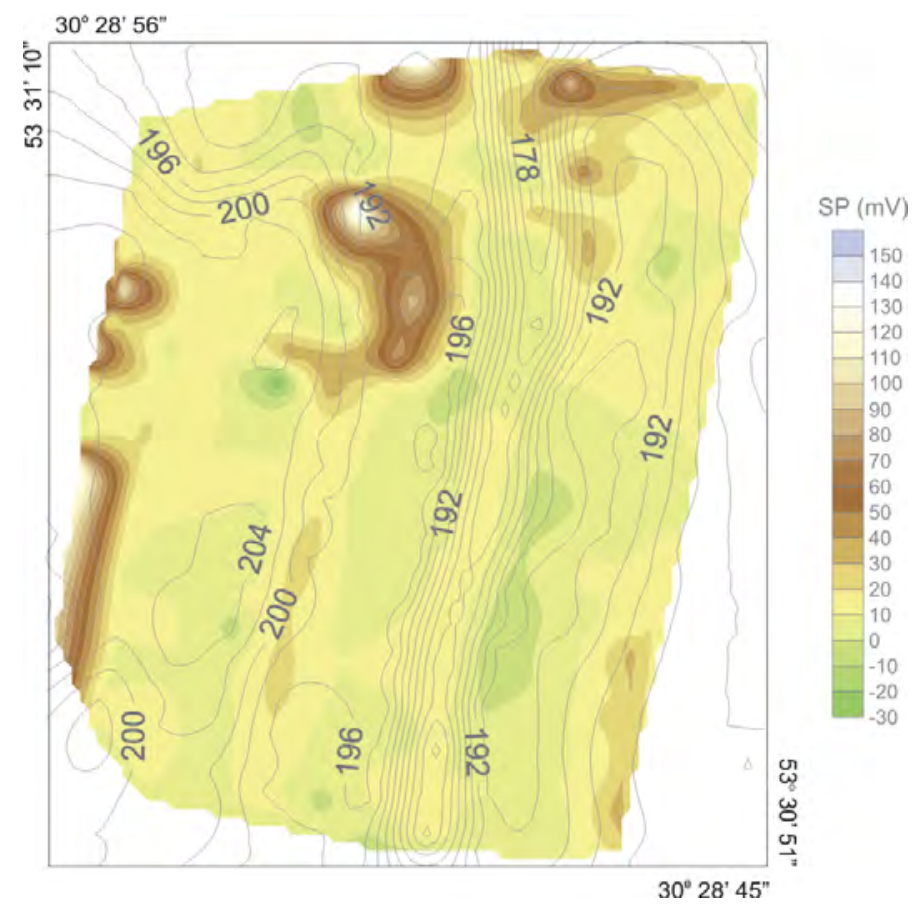

Figura 4. Mapa de potencial espontâneo com topografia.

Ambos os lados apresentam declividade no sentido da vala, que proporcionam um fluxo natural por gravidade. Nesse sentido ocorrem os valores de voltagem que tendem ao negativo. A teoria do método de potencial espontâneo descreve o fenômeno de geração de potencial elétrico associado à movimentação da água subterrânea (Lowrie, 2007).

Em contrapartida, a região com resíduos enterrados também apresenta valores de voltagem que tendem ao negativo, mas em área de topografia plana. Nesse caso, o potencial elétrico medido deve resultar predominantemente da atividade geoquímica de decomposição dos resíduos, ou seja, potencial de oxidação. Pontos localizados com voltagem elevada nessa área devem representar áreas com baixa taxa de decomposição, como concentrações de materiais inorgânicos (plásticos, papéis, borracha, dentre outros).

Com base nas informações de campo referentes à espessura de lixo em diversos pontos da área é possível afirmar que, nas seções modeladas, a faixa de valores entre $0 \Omega . m$ e $70 \Omega . m$ correspondem à cama de resíduos enterrada, possivelmente saturada em água e chorume. Os valores superiores a $70 \Omega$.m definem os anfibolitos e xistos que representam o substrato local (Figura 5).

A linha 8 também é caracterizada por baixos valores de resistividade, embora esteja localizada no limite do aterro, numa área com ausência de resíduos. Entretanto, essa linha está posicionada na parte mais baixa do aterro. É provável que essa linha receba um grande aporte de chorume proveniente das áreas elevadas, ou seja, as áreas cruzadas das linhas 1 a 7.

Existem anomalias verticalizadas de baixa resistividade posicionadas abaixo da camada de resíduos, interpretadas como áreas de acúmulo e fluxo de água subterrânea e chorume, devido ao posicionamento abaixo da camada de resíduos. As linhas de caminhamento elétrico foram posicionadas de forma perpendicular ao padrão de fraturamento local, ou seja, com direção N/S aproximadamente. Dessa forma, as áreas verticais de baixa resistividade devem corresponder a planos de fratura saturados em água e chorume (Figura 5). 
MOREIRA, C. A.; OLIVEIRA, M. T. de.; SILVA, A. C. da. Estudo geofísico em aterro controlado disposto sobre rochas fraturadas. Ambi-Agua, Taubaté, v. 6, n. 2, p. 180-190, 2011. (doi:10.4136/ambi-agua.193)
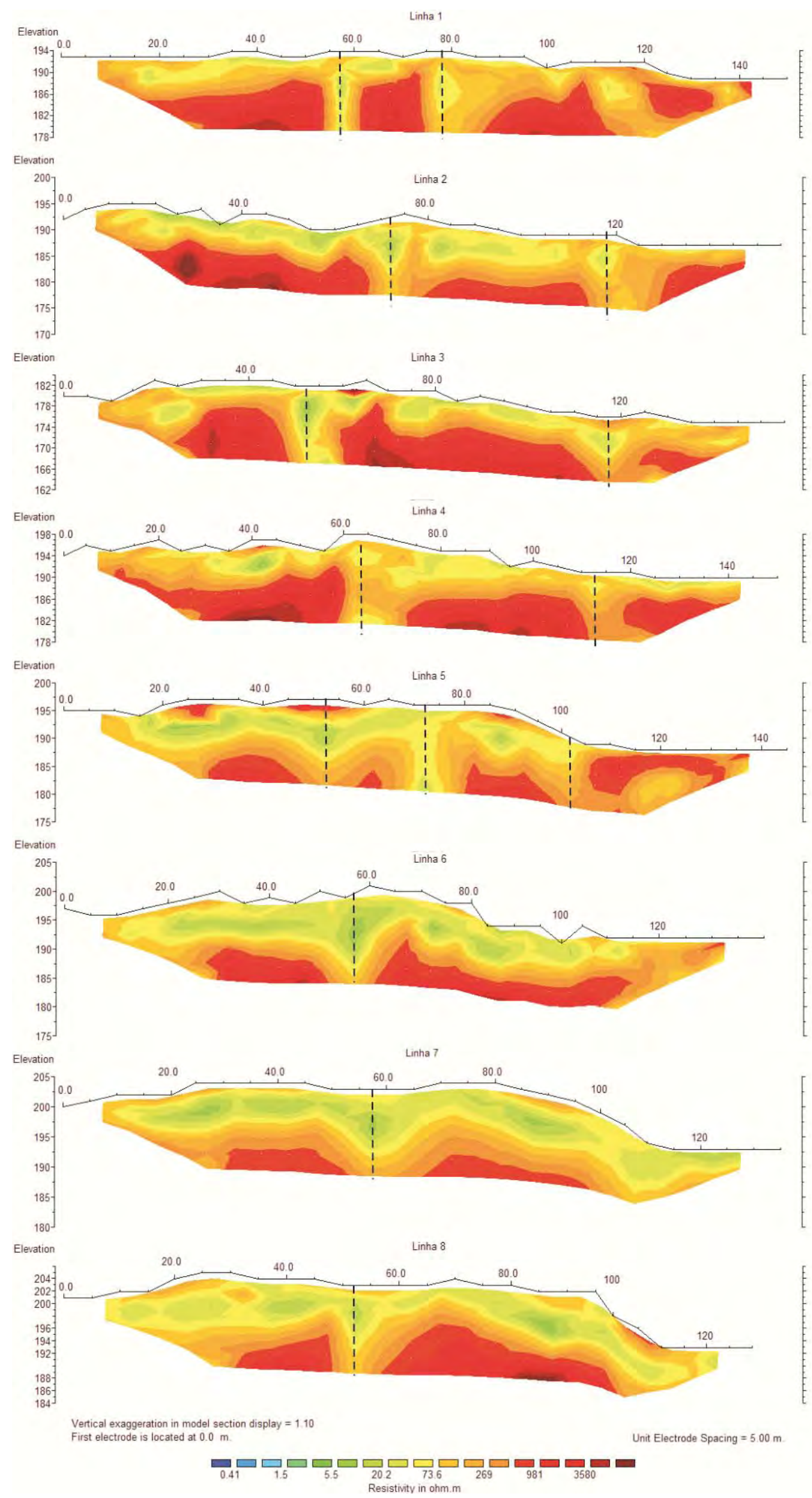

Figura 5. Modelos de inversão de medidas de resistividade, com posição aproximada dos planos de fratura principais (linhas tracejadas). 


\section{CONCLUSÃO}

O método de potencial espontâneo foi inadequado para identificação de áreas com provável concentração de chorume, devido à semelhança de valores entre a área do aterro e da área de pastagem adjacente. Não foi possível associar as anomalias negativas á degradação de resíduos orgânicos, ou seja, ao fenômeno de potencial de oxidação.

As anomalias de potencial espontâneo negativas são correlacionáveis à topografia da área, ou seja, o fluxo é direcionado das partes mais elevadas para uma vala que separa o aterro da pastagem, interpretado como potencial de fluxo.

A aplicação do método de eletrorresistividade na área de estudos permitiu caracterizar o intervalo com resíduos enterrados e a rocha sotoposta, devido ao contraste. Foi comprovado que a espessura de lixo aumenta gradativamente de oeste para leste. As seções corroboram esse fato, pois existe um aumento da espessura da faixa de baixos valores de resistividade também de oeste para leste.

Os resultados revelam baixos valores de resistividade elétrica no intervalo de presença de resíduos, corroborados em trabalho anterior (Moreira e Braga, 2009b; Moreira et al., 2009, Bortolin e Malagutti Filho, 2010; Santos et al., 2009). O intervalo atribuído à rocha é caracterizado por altos valores de resistividade, devido ao caráter inalterado. Os modelos de inversão apresentam anomalias verticalizadas de baixa intensidade principalmente nas posições de $60 \mathrm{~m}$ e $120 \mathrm{~m}$.

Valores de baixa resistividade verticalizadas principalmente na base do aterro estão relacionadas à presença de fluidos enriquecidos em sais dissolvidos. A decomposição da matéria orgânica contida nos resíduos sólidos, como restos alimentares, vegetais e animais, resulta em diversos subprodutos, dentre os quais o chorume. Esse subproduto é caracterizado pela elevada quantidade de sólidos totais dissolvidos, cuja migração e acúmulo em planos de fratura é fisicamente caracterizada como um condutor elétrico.

Os resultados alcançados neste trabalho demonstram a eficácia da geofísica em estudos hidrogeológicos para fins ambientais. A definição de padrões de fluxo em aquíferos fraturados é algo altamente complexo, principalmente por meio de formas diretas como poços de monitoramento ou abastecimento. Tais casos requerem formas de investigação multipontuais e que possibilitam investigações multidimensionais, algo perfeitamente possível com uso de métodos como a eletrorresistividade e eletromagnéticos.

A capacidade de dissolução de contaminantes inorgânicos nas águas subterrâneas, dentre os quais é classificado o chorume, resultam numa relação direta entre fluxo hidrogeológico e percolação de fluídos.

Essa relação não é valida para compostos orgânicos como gasolina, diesel e compostos organoclorados, imiscíveis e com relações de densidade distintas da água. Nesses casos é vital o entendimento de processos de atenuação natural e o comportamento dos principais subprodutos no meio geológico, para uma avaliação adequada de áreas contaminadas, conforme demonstram os trabalhos de Braga et al. (2008) e Moreira e Dourado (2005, 2007).

\section{AGRADECIMENTOS}

Agradecemos à Universidade Federal do Pampa pelo empréstimo do equipamento e à Prefeitura Municipal de Caçapava do Sul pelo acesso à área de estudos.

\section{REFERÊNCIAS}

BAEDECKER, M. J.; APGAR, M. A. Hydrogeochemical studies at a landfill in Delaware. In: . Groundwater contamination. Washington: National Academic Press, 1984. p. 127-138. 
BELL, F. G.; JERMY, C. A. A seepage problem associated with an old landfill in the greater Durban área. In: SARSBY, R. W. (Eds.). Waste Disposal by Landfill - GREEN'93. Rotterdam: A. A. Balkema, 1995. p. 607-615.

BENNETT, P.; SIEGEL, D. I. Increased solubility of quartz in water due to complexing by organic compounds. Nature, v. 326, p. 684 - 686, 1987.

http://dx.doi.org/10.1038/326684a0

BITENCOURT, M. F. Metamorfitos da região de Caçapava do Sul, RS: geologia e relações com o corpo granítico. In: SIMPÓSIO SUL-BRASILEIRO DE GEOLOGIA, 1., 1983, Porto Alegre. Anais... Porto Alegre: Sociedade Brasileira de Geologia, 1983. p.37- 48.

BORTOLIN, J. R. M.; MALAGUTTI FILHO, W. Método da eletrorresistividade aplicado no monitoramento temporal da pluma de contaminação em área de disposição de resíduos sólidos urbanos. Engenharia Sanitária e Ambiental, v. 15, p. 367-374, 2010.

BRAGA, A. C. O.; MOREIRA, C. A.; CARDINALLI, M. T. Variação temporal da resistividade elétrica em contaminação por gasolina. Geociências, v. 27, n. 4, p. 517525, 2008.

BRASIL. Ministério de Minas e Energia. Companhia de Pesquisa de Recursos Minerais CPRM. Programa Levantamentos Geológicos Básicos do Brasil. Cachoeira do Sul, Folha SH.22-Y-A. In: PORCHER, C. A.; LOPES, R. C. (Org.). Estado do Rio de Grande do Sul. Brasília: CPRM, 2000. 1 mapa. Escala 1:250.000.

BRASIL. Ministério de Minas e Energia. Companhia de Pesquisa de Recursos Minerais CPRM. Programa Levantamentos Geológicos Básicos do Brasil. Mapa geológico do Estado do Rio Grande do Sul. In: WILDNER, W.; RAMGRAB, G. E.; LOPES, R. C.; IGLESIAS, C. M. F. (Org.). Porto Alegre: CPRM, 2008.1 mapa. Escala 1:750.000.

CAÇAPAVA DO SUL. Prefeitura Municipal. Antigo Lixão - Relatório Final. Caçapava do Sul: PM, 1996. 42 p.

COMPANHIA DE TECNOLOGIA DE SANEAMENTO AMBIENTAL - CETESB. Manual de gerenciamento de áreas contaminadas. GTZ. 2. ed. São Paulo: CETESB, 2001. 389p.

CHRISTENSEN, T. H,; KJELDSEN, P.; ALBRECHTSEN, H. J.; HERON, G; NIELSEN, P. H.; BJERG, P. L. et al. Attenuation of landfill leachate pollutants in aquifers. Critical Review in Environmental Science and Technology, v. 24, n. 2, p. 119-202, 1994. http://dx.doi.org/10.1080/10643389409388463

ELIS, V. R.; BARROSO, C. M. R.; KIANG, C. H. Aplicação de ensaios de resistividade na caracterização do Sistema Aquífero Barreiras / Marituba em Maceió - AL. Revista Brasileira de Geofísica, v. 22, n. 2, p. 2004. Disponível em: <http://www.scielo.br /scielo.php?script=sci_arttext\&pid=S0102-261X2004000200001\&lng=en\&nrm=iso>. Acesso em: 09 maio 2011. http://dx.doi.org/10.1590/S0102-261X2004000200001.

GOOGLE EARTH. Versão 4.3 (beta). Washington, DC: Europa Technologies; US Dept. of State Geographer, 2010.

HAMADA, J. Estimativas de geração e caracterização do chorume em aterros sanitários. In: CONGRESSO BRASILEIRO DE ENGENHARIA SANITÁRIA E AMBIENTAL, 19., 1999, Foz do Iguaçu. Anais... Foz do Iguaçu: ABES, 1999. 
INSTITUTO BRASILEIRO DE GEOGRAFIA E ESTATÍSTICA - IBGE. Cidades@. 2009. Disponível em: <www.ibge.gov.br>. Acesso em: 02 dez. 2009.

INSTITUTO BRASILEIRO DE GEOGRAFIA E ESTATÍSTICA- IBGE. Pesquisa nacional de saneamento básico. Rio de Janeiro: IBGE, 2002.

JUCA, J. F. T. Disposição final dos resíduos sólidos urbanos no Brasil. In: CONGRESSO BRASILEIRO DE GEOTECNIA AMBIENTAL - REGEO'2003, 5., 2003, Porto Alegre. Anais... Porto Alegre: ABG, 2003. 1 CD-ROM.

LOKE, M. H.; BARKER, R. D. Rapid least-squares inversion of apparent resistivity pseudosections by a quasi-Newton method. Geophysical Prospecting, v. 44, p. 131152, 1996. http://dx.doi.org/10.1111/j.1365-2478.1996.tb00142.x

LOWRIE, W. Fundamentals of geophysics. 2. ed. Cambridge: Cambridge University Press, 2007. 381p.

MILSOM, J. Field geophysics: the geological field guide series. 3. ed. London: Wiley, 2003. 249p.

MOREIRA, C. A.; DORADO, J. C. Monitoramento da atenuação natural de pluma de contaminação pelo método de Radar de Penetração no Solo (GPR). Revista Brasileira de Geofísica, v. 25, n. 4, p. 389-398, 2007.

MOREIRA, C. A.; DORADO, J. C. Análise de contaminantes de fase líquida não aquosa (NAPLs) por aplicação do método Eletromagnético Indutivo (EM). Revista Brasileira de Geofísica, v. 23, n. 3, p. 213-220, 2005.

MOREIRA, C. A.; BRAGA, A. C. O.; FRIES, M. Degradação de resíduos e alterações na resistividade elétrica, pH e Eh. Revista Brasileira de Geofísica, v. 27, n. 2, p. 283 293, 2009.

MOREIRA, C. A.; BRAGA, A. C. O. Aplicação de métodos geofísicos no monitoramento de área contaminada sob atenuação natural. Revista de Engenharia Sanitária Ambiental, v. 14, n. 2, p. 257 - 264, 2009a.

MOREIRA, C. A.; BRAGA, A. C. O. Caracterização geoelétrica de contaminantes provenientes da decomposição de resíduos sólidos domiciliares. Revista Ambiente \& Água, v. 4, n. 2, p. 106-114, $2009 \mathrm{~b}$.

POSSAMAI, F. P.; VIANA, E.; SCHULZ, H. E.; COSTA, M. M.; CASAGRANDE, E. Lixões inativos na região carbonífera de Santa Catarina: análise dos riscos à saúde pública e ao meio ambiente. Ciência \& Saúde Coletiva, v. 12, n. 1, p. 171-179, 2007.

SANTOS, A. A.; SHIRAIWA, S.; SILVINO, A. N. O.; SILVA, W. P. S.; SILVA, N. A.; SILVEIRA, A. et al. Comparação entre a investigação direta da água subterrânea e Radar de Penetração no Solo (GPR) na área do aterro sanitário de Cuiabá (MT). Revista Brasileira de Geociências, v. 39, n. 4, p. 768-722, 2009. 